\title{
Philosophical Method and Galileo's Paradox of Infinity
}

\author{
Matthew W. Parker \\ Department of Philosophy, Logic and Scientific Method \\ London School of Economics
}

You are free, therefore choose- that is to say, invent.

Sartre, L'existentialisme est un humanisme

Philosophy, and especially metaphysics, has often been attacked on either epistemic or semantic grounds. Anything outside of experience and the laws of logic is said to be unknowable, and according to Wittgenstein and the logical positivists, there are no such things to know; metaphysical disputes are either meaningless or merely verbal. This was thought to explain philosophy's supposed lack of progress: philosophers argue endlessly and fruitlessly precisely because they are not really saying anything about matters of fact (Wittgenstein 1953, Remark 402; Carnap 1950).

Since the mid-twentieth century, the tide has been against such views, and metaphysics has re-established itself within the analytic tradition. Ontology, essentialism, and de re necessity have regained credibility in many eyes and are often investigated by excavating intuitions of obscure origin. Relatedly, externalist semantic theories have claimed that meaning or reference has a secret life of its own, largely unfettered by our understanding and intentions (Kripke 1971; 1972; Putnam 1973; 1975a). 'Water', it is claimed, would denote $\mathrm{H}_{2} \mathrm{O}$ even if we had never discovered that particular molecular structure, and this is allied with the 
view that such structure is metaphysically essential to water-that water could not have been otherwise (Kripke 1971; 1972).

I wish to explore a third way, an approach to philosophical problems that is sympathetic to Wittgenstein and the positivists' diagnosis of philosophy (" $[\mathrm{P}]$ hilosophical problems arise when language goes on holiday," 1953, Remark 38), while rejecting their gloomy prognosis and Wittgenstein's anti-interventionist prescription ("Philosophy leaves everything as it is," 1953, Remark 124). I will call this third way the Method of Conceptual Articulation (MCA). In general, it consists in refining or modifying concepts, or engineering altogether new ones, so that an apparently "empty" question acquires a satisfying answer-or if you prefer, so that some related, more specific question emerges that has a definite answer and is relevant to some motivation. ${ }^{1}$ When we find that we have posed a question that we ourselves do not entirely understand, we should not demand, 'Still, what is the true answer?' but step back and ask, 'What more precisely would we really like to know?' In this way, even questions that are metaphysical in the pejorative Viennese sense, questions with no factual answers (if such there be), can nonetheless be answered, for they can be given cognitive content, ${ }^{2}$ and perhaps in a well motivated way. By refining or modifying our concepts and questions, I think we can "fill” some initially empty questions, and even solve philosophical problems, which I define here as finding definite answers that are relevant to our motivations.

This approach is partly inspired by, and endorses, a certain libertarianism that one

\footnotetext{
${ }^{1}$ The MCA has many precedents, perhaps most clearly in Carnap 1950. But there the connection between ontology and language choice was treated as another way to dismiss metaphysics rather than rehabilitate it.

${ }^{2}$ Of course, this depends on how we individuate questions. If we suppose that any change in cognitive content (induced by a change in language or theory) implies that we are dealing with a different question, then trivially the content of a question can never change. But this seems to be a purely verbal issue; I do not think anything here rides on it.
} 
finds in the views and practices of at least some modern mathematicians, namely the view that we are free to develop concepts and introduce objects as we wish, provided they do not spawn inconsistency. As Cantor put it, "Mathematics is entirely free in its development, bound only by the self-evident concern that its concepts be both internally without contradiction and stand in definite relations, organized by means of definitions, to previously formed, already existing and proven concepts" ([1893] 1976, 79). On that view, whatever we can consistently define is a legitimate object of study. More recently, Wilder wrote of modern abstract algebra,

From this it is evident that the modern mathematician has lost the qualms of his forebears regarding the 'reality' of a 'number' (or other mathematical entity). His criteria of acceptance are of a completely different sort, involving such matters as consistency, utility of the concept, and the like. $(1968,148)$

On that view, the reputed uncritical realism of working mathematicians does not in general limit their freedom, for it is no longer reserved for intuitively appealing structures like the natural numbers or Euclidean space. One internally consistent concept or mathematical theory is no more true or real than another. Hence Cantor wrote that if a proposed object satisfies his above conditions, "mathematics can and must regard it as existent and real" (ibid.). To be sure, many mathematicians are concerned not only with consistency but with the legitimacy of the objects they introduce, in some broader sense that may depend on utility, intuition, elegance, and so on. Such practical and aesthetic concerns may even provide some evidence of consistency, which itself is usually quite difficult to prove, but they are not the same thing as consistency, much less reality or truth. For the libertarian, there $i s$ no question of the truth for a definition or axiom, for such things make no claim of fact. They only stipulate linguistic conventions and determine a domain of discourse. 
As evidence that this has become a popular view among mathematicians, I would cite the emergence of non-Euclidean geometries, the trend in function theory from more to less restricted concepts of function (Jourdain 1906-13; Maddy 1993; 1997) and the ascendance of the big-tent notion of set that Maddy calls Combinatorialism (op cit.), the latter two of which Cantor himself played important parts in. But if the reader is unconvinced, no matter; nothing I have to say here depends on it. I mention this libertarianism only to illustrate the kind of approach I have in mind, and as a significant element in Cantor's views, which we will discuss at length. If libertarianism and the related MCA do not reflect the views and practices of most mathematicians, I would urge them to reconsider. We should study mathematical practice to determine what works and improve our understanding of mathematics. We should not regard the prevailing practice as sacred.

I believe that several philosophical problems have already been solved by means approximating the MCA, but rarely deliberately. Those who have solved philosophical problems by articulating new concepts have typically thought that they were discovering deep facts, not stipulating definitions. Still, in several cases, a problem was in fact solved by articulating concepts that addressed concerns more specific than the initial question. One example was the problem of the world systems, ultimately put to bed by Newton's refinement of the concept of motion and his successful theory of gravitation. ${ }^{3}$ Another lies in recent extensions of decidability to the continuous context (Myrvold 1997, Parker 2003, 2005, 2006). A more overtly metaphysical example that quite clearly employs the MCA is Parfit's work on

\footnotetext{
${ }^{3}$ DiSalle $(2002 ; 2006)$ reads Newton's Scholium to the Definitions in the Principia as giving a definition (presumably stipulative) of absolute space and absolute motion. This would fit wonderfully with my methodology, but it does not seem to fit Newton's text. Newton seems rather to have made metaphysical claims about absolute space and motion. Still, such claims performed the function of giving those notions empirical content and rendering the Copernican question determinate.
} 
personal identity $(1971 ; 1984)$. I hope to discuss these and other examples elsewhere. The one I will consider here is Cantor's extension of the concept of number to the transfinite, and the resolution this supplies for "Galileo's Paradox"4 (Galileo [1638] 1954), namely that the square numbers seem to be at once fewer than and equal to the positive integers. ${ }^{5}$

There, too, the MCA was not applied deliberately. The historical figures discussed below-Galileo, Bolzano, and Cantor-did not see themselves as altogether freely stipulating useful new conventions, but either as drawing conclusions about the relative size of infinite collections, or, in Cantor's case, as extending the concept of numerosity ${ }^{6}$ in a constrained way. Nonetheless, key elements of the MCA are reflected in some of their remarks and arguments. I will argue in light of their writings that, whatever those authors may have thought, questions of transfinite numerosity were in certain senses indeterminate, and Cantor's extensions of numerosity were stipulated more freely than some of his remarks would suggest. His stipulations - in particular the notion of power-not only served to resolve Galileo's Paradox (which Galileo and Bolzano had also done, in different ways), but at least partially solved the broader philosophical problem of transfinite numerosity insofar as it helped to address major background concerns. The main evidence that the MCA can work, then, is that it has worked. (Note that I do not claim that the MCA is part of standard mathematical

\footnotetext{
${ }^{4}$ The paradox far pre-dates Galileo; see note 18. I use the word 'paradox' throughout in the sense of a contradiction engendered by otherwise plausible suppositions. (Assuming the law of non-contradiction, I do not see what else a paradox could be.)

${ }^{5}$ Cantor himself paid little attention to that paradox, but he did present a version of it (with the square numbers replaced by the even numbers), not as a paradox but merely an illustration of a property of powers (1878, 242-

3). He also alluded to the some phenomenon in a couple of other places, as we will see.

${ }^{6}$ Throughout this essay I use 'numerosity' to denote the general notion of cardinal number, i.e., number-ofelements, without presupposing Cantor's analysis of that concept. Cantor's "cardinal number" will be called power, as he initially called it.
} 
practice, only that it, or something quite close to it, has been successfully applied to some philosophical problems, in mathematics and elsewhere.)

If indeed the MCA has sometimes been successful in the realm of mathematics, there is a further question as to whether it can be (or as I suggest, already has been) useful in more general metaphysics. Of course, the problem of the infinite is traditional metaphysics par excellence. Nonetheless, I will not argue here for the broader applicability of the MCA. I have mentioned some applications that I wish to discuss elsewhere, and I hope to apply it to others as well. The broad success of the method can then be evaluated in terms of those applications. Here let us bracket that question and focus on mathematics.

In Section I, I further articulate and contextualize the method. I describe a roughly Wittgenstinian picture of concepts and Cantor's related notion of concept splitting. I then state a naïve version of the method, raise some possible objections, and finally mention a modified method that avoids most of the difficulties. Section II reviews Galileo's Paradox and his motivations for presenting it. There I argue that, in concluding that the concept of relative size cannot be applied to the infinite, he was in a certain sense right, and Cantor, in claiming that there is no contradiction in cases like Galileo's Paradox, was wrong. ${ }^{7}$ In Section III, I review Bolzano's position, that proper subsets are always smaller and bijection is not sufficient for equinumerosity. I argue from Duggan's (1999) order extension theorem that Bolzano was not simply mistaken; the relation of proper subset can be extended to a general concept of number quite different from Cantor's. Section IV evaluates Cantor's methods, his own perspective on his work, and the success of his theory in addressing some major concerns common to all three of our historical figures. Section V briefly criticizes

\footnotetext{
${ }^{7}$ This is not an attack on Cantor's theory. The point is just that his theory required a conceptual innovation in order to escape Galileo's Paradox (and it was not the only such innovation possible).
} 
Gödel's arguments for absolutism about the concept of cardinal number and touches on some more recent debates about realism in mathematics. Section VI concludes with brief summary remarks.

\section{THE METHOD}

The approach to philosophical problems considered here emerges from a certain picture of concepts and of how philosophical problems arise, a picture derived from Wittgenstein, Waismann, and to some extent Kant. [Kant suggested that the antinomies arise from stretching our concepts beyond their proper domains ([1781] 1998, Aii ff.), an idea anticipated by Galileo ([1638] 1954, 31, quoted below).] Elements of this picture can even be found in Cantor's remarks, as we will see.

Wittgenstein pointed out in the early sections of the Investigations (1953) that many of our concepts do not have any tidy set of necessary and sufficient conditions. He used the metaphor of a rope, which derives its unity from its many overlapping fibers rather than a single pervasive thread. Another apt metaphor would be that of a well worn rag. Typically, our informal concepts are woven of many strands: various conditions or properties, similarities between instances, and different approximately equivalent characterizations. They fray at the edges, where borderline cases arise (“degree vagueness," as Alston called it in 1964). They also have holes: cases that do not lie on a fuzzy boundary but rather are omitted from classification altogether (“combination-of-conditions vagueness", ibid.). ${ }^{8}$ They can be

\footnotetext{
${ }^{8}$ Alston's "degree vagueness" is the sorites type, consisting in "the lack of a precise cut-off point along some dimension" $(1964,87)$, while "combination-of-conditions vagueness" consists simply in the indeterminacy of the truth conditions for a term (87-88). Waismann's famous notion of open texture (1945) is related. Originally called porosität-literally, 'porosity'—it is, on one reading, just what I mean by holes, i.e., combination-ofconditions vagueness. But as Ackerman (1994) points out, Waismann further distinguishes open texture as ineliminable; no definition can completely remove it. Our rag picture is partly motivated by a suspicion that such
} 
stretched to cover new cases, but, as Cantor noticed, stretched too far they will tear (Figure 1). When we extend a concept beyond its usual domain, we may find that it comes apart, so that some characteristic conditions are no longer mutually consistent, or various formulations are no longer equivalent.

Cantor pointed out just such a case. He of course extended the concept of number in two directions, that of $A n z a h l^{9}$ (later called ordinal number) and that of power (Mächtigkeit, later called cardinal number). For any finite set, Cantor observed, Anzahl and power coincide and determine each other, but not so for the infinite; two infinite sets can have the same power but different Anzahlen. Hence, as Cantor put it, "the whole concept of number...in a certain sense splits up into two concepts when we ascend to the infinite" ([1883b] 1976, 78, Cantor's emphasis). In fact, it splits into more concepts than that, for other notions of transfinite number are possible, as I will explain in Section III. (Besides those discussed here, another alternative notion is given in Buzaglo 2002.)

When concepts split, we may be puzzled as to what we really had in mind in the first place. Which criteria truly characterize the original notion? But this is often a misguided ineliminable vagueness exists and is even the rule, but that is inessential to the present considerations. Such vagueness should also be distinguished from outright category errors. The emptiness of 'What time is it on the sun?', for example, is not due to vagueness but to a definite inapplicability. Nonetheless, it seems we could modify the concept of time-of-day to cover that case.

${ }^{9}$ Cantor also described order type (a generalization of Anzahl) as the natural extension of the concept of number ([1895-7] 1915, 117).

There is some disagreement about the sense of 'Anzahl' in Cantor's hand. Ordinarily this word is translated as 'number,' 'cardinal number,' or 'number of elements,' contradicting Cantor's later designation of his Anzahlen as the ordinal numbers. Tait (2000) on the other hand, reads Anzahl as 'counting number,' and elsewhere (1996) treats this as a synonym for 'ordinal.' Cantor did refer to an Anzahl as the result of counting ([1883] 1976, 75), but note that this is consistent with regarding it as a measure of numerosity (relative to an ordering). To avoid any anachronism or prejudice, I will simply use 'Anzahl.' 


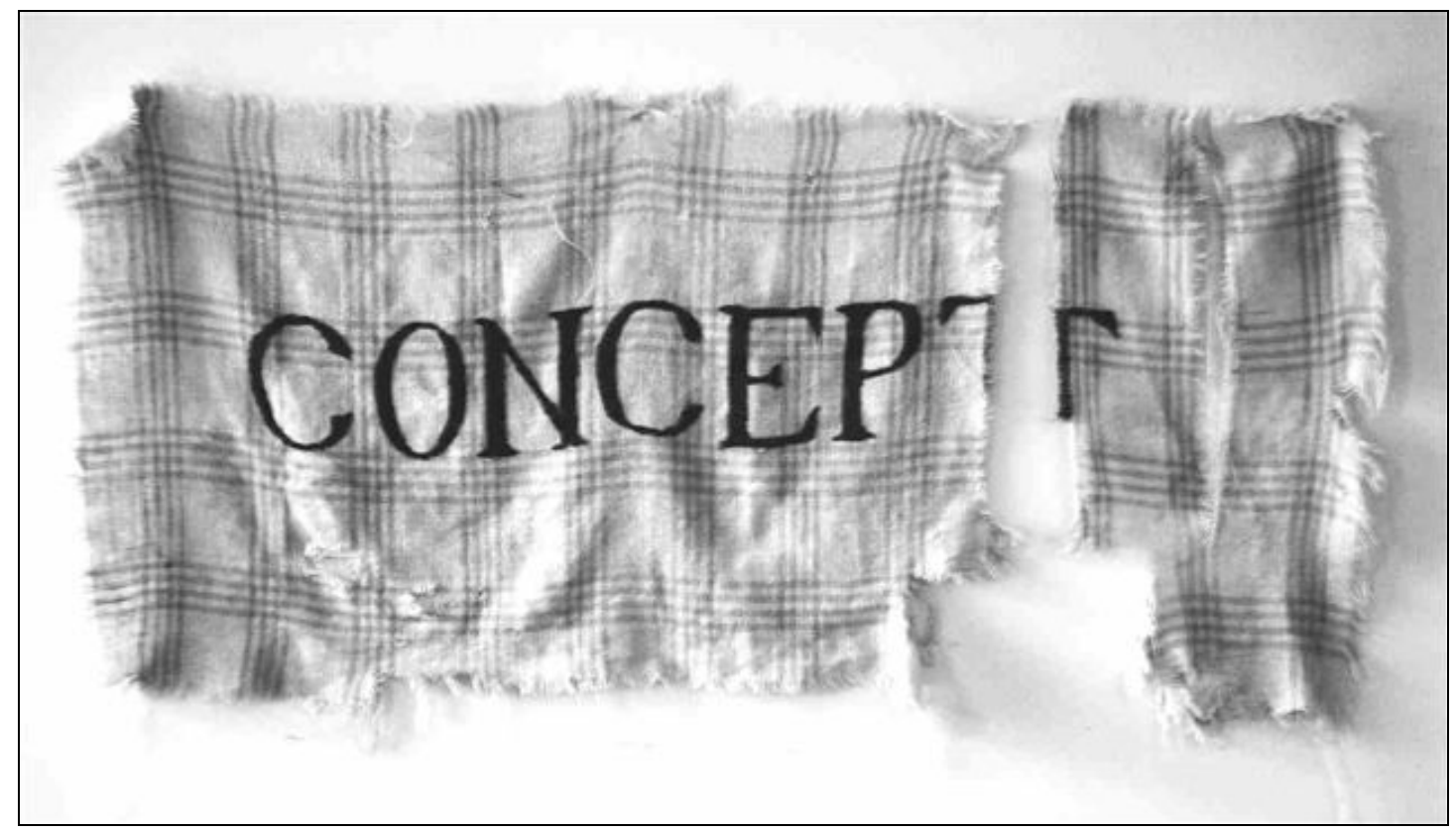

Figure 1. A concept that has been stretched too far.

question. The original appeal of the concept, in its established domain of application, may have been due to the concurrence of several conditions or characterizations. For example, part of the value of ordinal number, in the sense of 'position in a sequence, ${ }^{10}$ is that for finite sets it coincides with cardinal number or numerosity. This after all is what makes it possible to count; we correlate finite numbers with the elements of the set being counted, and the last position we reach in the sequence of numbers indicates the numerosity of the set. Thus, both cardinal number and ordinal, and the fact that they concur, and as well the condition that proper subsets are always smaller-all of these and more are what truly characterize the original concept of number. When such concurrent conditions diverge, there may be no uniquely right way to extend the concept, and hence a question that stretches a concept beyond its usual domain may have no uniquely correct answer. To obtain answers, we have to refine or

\footnotetext{
${ }^{10}$ Cantor's "ordinal numbers" are not merely positions in a sequence. They are ordered sets of "units" that represent the "order type," in effect the structure, of a well-ordered set ([1895-7] 1915). They are not the grammarian's ordinals.
} 
modify the concepts involved.

So far we have made free use of the notion of "the concept of $X$," but this requires clarification on a number of fronts. In general we will use 'concept' to denote some disjunction of conditions. Like Frege, we have in mind a logical object, not a psychological one. But to speak of the concept of number, for example, leaves open the question of which conditions count. They might be those associated with the word 'number' by everyone in some community, or by the "competent" speakers of a language (which requires further clarification), or by a particular individual. They may be the conditions regarded as constituting the meaning of 'number,' or they may include all commonly held beliefs about number. Or, the concept of number might be something more objective, a somehow distinguished set of conditions that we may not even be aware of. These distinctions will be helpful in understanding the views of our historical figures.

Like typical concepts, the MCA can be refined in various ways. One naïve version is as follows:

\section{The Naïve Method of Motivational Analysis (NMMA)}

(1) Establish that the question at hand, as stated, has no uniquely determined answer.

(2) Identify background motivations for the question, either practical or theoretical.

(3) Refine or extend the concepts involved in the question so that under the amended concepts, the question does have a determinate answer and is relevant to the background motivations.

Some clarifications are in order.

There are different senses in which a question can have no unique answer. Olson (2006) suggests that even vague questions have definite answers, for if a case is vague, then the assertion of vagueness is itself the uniquely correct answer. But if we ask, as in our example below, 'Is $A$ greater than $B$,' then 'The question is vague' is not in the normal sense an answer to the question, for the question presupposes an answer of 'yes' or 'no.' The assertion 
of vagueness is just a way of denying that there is a uniquely correct answer. Other responses, such as 'Those terms do not apply,' and 'Only to degree $x$,' are quite different from the former. They do not assert semantic indeterminacy, but a category error; they imply an established usage that definitely rules out a simple yes-or-no answer. Such differences impinge on the nature of a conceptual amendment, for if the question is genuinely indeterminate, there is room to refine or extend concepts without transgressing established limits on usage, but not if the question commits a definite category error. Still, even if a particular application of a concept or word is definitively ruled out, we may be to extend its domain nonetheless, changing its content. (I will explain shortly why this is not obviously true.) The main purpose of step (1), besides removing the temptation to keep looking for straightforward answers (e.g., yes or no), is to prevent us revising concepts that are already doing good work (though sometimes non-cumulative revisions are necessary). But there does not appear to be much danger in extending a concept beyond previously imposed limitations of scope, however definite, so long as logical consistency is maintained.

A question that arises about step (2) is, whose motivations should we consider? ${ }^{11}$ The method is intended to serve those who apply it, so in using it one should consider one's own motives. But we can choose our motives, and one might choose to address someone else's concerns. So in general, the goals considered might be anyone's or even no one's, but the success of a conceptual innovation or refinement - the question of whether it constitutes a solution in the sense I have given-is then relativized to those goals. To address the historical question of whether the method was successfully applied to a particular problem, we merely ask whether anyone's motives were considered, and whether the sharpened question addressed those motives. It matters little, for that purpose, whose motives they were, but then

\footnotetext{
${ }^{11}$ Thanks to an anonymous referee for raising this issue.
} 
the resulting answer is only a solution relative to those motives. In the present case, we will see that all three of our historical figures had related motives that were indeed addressed by Cantor's solution.

When we can apply the NMMA, we really ought to. The steps themselves imply that the method will succeed in a way that addresses what is important to us, as long as the steps can be carried out, and step (1) protects us from doing damage to other useful concepts and theories. But there are several reasons to worry whether the method can be executed. The presupposition that we can determine whether a given question has a unique answer is challenged by Quine's attack on the analytic/synthetic distinction (1951), externalist semantics (Kripke 1971; 1972; Putnam 1973; 1975a), and the mere fact that analytic philosophers have struggled a hundred years or more to discern meanings and meaningfulness, with limited success. The threat from externalism is that we might not have epistemic access to the meaning or reference of our own expressions. If water denoted $\mathrm{H}_{2} \mathrm{O}$ long before hydrogen and oxygen were even discovered, as Kripke and Putnam claim, then how can we be sure what our own words denote, and hence whether a given question is really empty or not? The NMMA also presupposes the apparent truism that we are masters of our own language — that we can revise our concepts to make our expressions mean whatever we want. This too is challenged by a form of externalism, namely Lewis's notion of a reference magnet, something that draws reference to it in virtue of its natural "eligibility" (1983; 1984; Hodes 1984; Sider 2001; forthcoming). How strong after all are these magnets, and can we override them?

A further worry is that we might not be able to perform step (2), to identify motivations more specific than the initial question. In fact, it is characteristic of philosophy and pure science that the main goal is extremely general: to understand. In the spirit of pure investigation we often pose puzzles without knowing exactly what we are looking for or having any specific purpose in mind. Wittgenstein provides an apt (and peculiarly bawdy) illustra- 
tion: many problems are "like the problem set by the king in the fairy tale who told the princess to come neither naked nor dressed, and she came wearing fishnet...He didn't really know what he wanted her to do, but when she came thus he was forced to accept it" (from a lecture quoted in Ambrose 1959). ${ }^{12}$ Moreover, even if there are distinct background motivations, it may be very difficult to discern them until after a solution is given. Otherwise there would not be much of a philosophical problem.

Supposing we can identify motivations, the final step is to construct concepts that will make our question determinate and relevant. In some cases this may be easy, but in others, it may require superhuman foresight, and this likely describes Cantor's case. Among the background motivations for his theory were desires to understand the structure of continuous spaces and other infinite point sets, the representability and integrability of functions, and the relations between numerosity and geometric magnitude (e.g., length or volume). ${ }^{13}$ To foresee that the concept of power would be so useful to those ends would have required genius beyond even Cantor's, and as we will see, Cantor only recognized the great importance of the concept, and adopted it as a notion of number, gradually, as applications occurred and a rich theory developed.

A final grave worry is that the method does not accurately describe the history of the example under consideration: Galileo's Paradox and its resolution. Indeed, for the most part it does not fit the views of the participants. But I will argue that in fact, extensions of the concept of numerosity were freely stipulated; that Cantor developed his concepts of numerosity gradually, in light of motivations, applications, and results; that he had certain motivations

\footnotetext{
${ }^{12}$ I do not, like Wittgenstein, think this characterizes all mathematical problems, but many philosophical ones.

${ }^{13}$ As we will discuss, Ferreirós (2004) argues that Cantor's dominant motivations lay not in mainstream mathematical concerns like function theory but in metaphysics and natural philosophy. However, he certainly had these more specific mathematical goals as well, and some were stimulated by his broader motivations.
} 
in common with Galileo and Bolzano; and that his concepts of numerosity proved particularly pertinent to those motivations.

Some of the above difficulties can be avoided by restricting our attention to matters of logical consequence rather than truth. Given a particular set of concepts, expressed as a set of propositions, i.e., a theory, we may well be able to determine whether or not an answer to a given question follows from that theory, along with other, uncontroversially determinate propositions ${ }^{14}$ and the standard laws of logic (or some other set of laws if you like). We need not distinguish between definitions in the theory and factual hypotheses; just throw them all in. Whether or not there is a genuine analytic/synthetic distinction, the determinacy of the answer to a question relative to a given theory does not depend on it. We need only remember that such determinacy or indeterminacy is then relative to a theory (and the laws of logic employed, if those are not in fact immutable). Furthermore, reference no longer enters into the matter. Even if we cannot tell whether reference determines an answer to our question, we may still be able to establish logical independence. We need only find two models of the theory which give different answers to the question.

We could generalize our method further and avoid even more of the difficulties. Given a seemingly unanswerable question, we might proceed roughly as follows:

\footnotetext{
${ }^{14}$ We may simply stipulate a set of propositions assumed to have determinate truth values. For the logical positivists, these were observations or sense data; for Newton's problem of giving empirical meaning to absolute motion, they would have been the propositions of relative position and motion; here they include the relations of relative size among finite sets, and the relations of proper subset-hood and 1-1 correspondence among infinite sets.
} 


\section{The Generalized Method of Theory Revison (GMTR) ${ }^{15}$}

(1) Propose a theory.

(2) Attempt to deduce an answer to the question.

(3) Evaluate the fruits of the theory (especially the motivations that it serves).

(4) As with shampoo, repeat as necessary.

Here we omit the step of showing that the question has no determinate answer, for even if it does, we can, if we wish, just propose a new theory that better serves our motivations. We also avoid the problem of identifying our background motivations and engineering appropriate concepts in advance. We can just as well propose a theory first and then examine the interests that it serves. Note that the purpose of step (3), 'Evaluate the fruits,' is not to judge the legitimacy of a theory or conceptual innovation, much less its truth or reality. In the context of mathematics, that would contradict the libertatianism I have advocated above: the claim that one logically consistent mathematical concept is no more real or true than another. But we are concerned here with developing concepts or theories that serve our motives. The point of step (3) is to determine whether the problem has been solved in that sense.

The question of whether we can override reference magnets is still troubling. We may propose a theory that answers our initially mysterious question, but reference magnetism might imply that the resulting theory is not in fact about its intended subject, and it may consequently be false even if it is true of its intended subject. However, it is hard to see how such considerations would bear on our understanding. Say for example we want to have a theory about a clear liquid with molecular structure XYZ. We construct a theory of XYZ and deduce lots of enlightening consequences. But suppose that, despite our intentions, the theory is really about $\mathrm{H}_{2} \mathrm{O}$, because $\mathrm{H}_{2} \mathrm{O}$ is a very strong reference magnet, and suppose our

\footnotetext{
${ }^{15}$ Of course, this is just the standard hypothetico-deductive method of empirical science, with the usual step of testing predictions radically generalized to "Evaluate the fruits," but it is meant to apply as well to mathematical and philosophical theories, in order to evaluate, not their truth, but their interest and usefulness.
} 
theory is false with regard to $\mathrm{H}_{2} \mathrm{O}$. What does it matter? The consequences we have deduced are still true of their intended referent, as desired. If somehow they are not true simpliciter, that would seem, in this case, to be an irrelevant technicality. How can reference matter here if it plays no role in our understanding or our use of language ${ }^{16}$

In any case, the GMTR fits more easily than the NMMA with historical examples, including the one discussed below. Cantor did not argue that the question posed by Galileo's Paradox was initially empty, nor regard himself as freely stipulating the nature and existence of transfinite numbers, but he certainly did propose a new theory that provided a solution to the paradox, derive consequences, and evaluate the fruits. Of course, this is not saying much. The GMTR is so loose that nearly any theoretical development will instantiate it. The important point is that mysterious philosophical questions can thus be made determinate and relevant to our concerns. By augmenting or revising our language or theory, we can obtain answers that bear on our broader purposes. ${ }^{17}$

However, the GMTR does not so much resolve our difficulties as dodge them, and by abandoning step (1) of the NMMA, it threatens to undo with willy-nilly revisions as much progress as it achieves. In what follows I will leave the GMTR aside and try to exhibit the

\footnotetext{
${ }^{16}$ I have ignored here serious questions about just what a theory of reference is supposed to assert—whether it makes genuine claims of fact or rather proposes a convention of interpretation, whether it is supposed to be completely adequate or a limited toy model, etc. (One might argue that we can diagonalize our way out of any given theory of reference just by stipulating that in certain cases reference will work differently.)

${ }^{17}$ There are further questions as to which propositions are essential to a theory, and which ones are not only determined by the theory but meaningful in some further sense. We might, for example, add to Newton's theory of gravitation the statement 'Discontent is orange,' making that sentence part of a useful theory, but in a clearly ad hoc and unhelpful way. We would like to have some way of distinguishing such inessential appendages to a theory from its integral, functional elements, but that is essentially the problem that hobbled logical positivism (Hempel 1950) even before Quine's “Two Dogmas" (1951). Perhaps the "evaluate" and "repeat" steps of the GMTR can help, but I make no attempt to resolve the problem here. I only make the modest claim that a statement can sometimes gain determinacy and relevance in virtue of a new concept or theory.
} 
extent to which the resolution of Galileo's Paradox can be assimilated to the NMMA or something close to it. But I will focus on logical implication, ignoring worries about externalism and reference magnets until we reach the discussion of Gödel's realism. After all, if, as I argue, something close to the NMMA has in fact worked, there is little to fear from the objections I have mentioned.

\section{GALILEO}

Galileo points out in his last dialogue $([1638] 1954,32)$ that the square numbers $(1,4$, $9,16, \ldots)$ are clearly fewer than the "numbers" (the positive integers $1,2,3,4 \ldots$ ), for the latter include the squares as well as many more. Yet, he goes on to show, these two collections are equal, since they can be placed in a one-to-one correspondence; just match each square with its root. So the two collections are at once equal and unequal. ${ }^{18}$ Galileo's protagonist Salviati concludes that infinities "transcend our finite understanding" (26), and "the attributes 'equal,' 'greater,' and 'less,' are not applicable to infinite, but only to finite, quantities"' (32). ${ }^{19}$

Some may regard this as simply a naïve mistake, though excusably so, given its date. Not all readers will agree, but often it is taken for granted that Cantorian set theory resolves

\footnotetext{
${ }^{18}$ There is a nearly continuous family of similar paradoxes going back to the distantly related Wheel Paradox from around the $4^{\text {th }}$ century BCE (Sambursky 1959; Murdoch 1982; Gardies 1984; Duhem [1954] 1985; Thomas 1958; Rabinovitch 1970). Notably, Duns Scotus, around 1302, compared the odd and the even numbers to the whole numbers and even anticipated Cantor in rejecting what we will call Euclid's Principle (Gardies 1984, 45-6). Gregory of Rimini, around 1346, adopted an approach surprisingly close to the MCA: he distinguished two senses of 'larger,' the “improper" one corresponding to Euclid's Principle, and the "proper" corresponding to what we will call Hume's Principle (Duhem [1954] 1985, 111-12). However, he offered this more as a conceptual analysis than an innovation, and still suggested by his 'proper/improper' terminology that the Humean notion of larger was the uniquely correct one.

${ }^{19}$ According to Duhem ([1954] 1985, 89ff.), this was also held by Duns Scotus and several subsequent medievals.
} 
the paradox in the only way possible. As we now know, some will say, two sets are equal in numerosity if and only if they can be placed in one-to-one correspondence. The fact that the set of integers is thus equal to a proper subset of itself is just an odd phenomenon characteristic of infinite sets, which any suitably modern and open-minded individual will accept once accustomed to it. Gödel ([1947] 1983) held this view, and Cantor himself said, "There is no contradiction when, as often happens with infinite aggregates, two aggregates of which one is a part of the other have the same cardinal number," and further, "I regard the non-recognition of this fact as the principal obstacle to the introduction of transfinite numbers" (quoted in Jourdain 1915, 75; my emphasis).

But in a clear sense, Salviati was right and Cantor was wrong.

The concept of relative size with which Salviati and his author were equipped, taken in whole, cannot be applied consistently to infinite sets. For Galileo, these concepts involved at least two principles:

Euclid's Principle (Common Notion 5): The whole is greater than the part (i.e., strictly greater than any proper part).

Hume's Principle: Two collections are equal in numerosity if and only if their members can be put in one-to-one correspondence. ${ }^{20}$

\footnotetext{
${ }^{20}$ Galileo did not spell out these principles, let alone call them by these names, but they are clearly implicit in his statement of the paradox.

In recent debates on neo-logicism (e.g., Hale and Wright 2001, Demopoulos 2006), 'Hume's Principle' usually refers to Frege's implicit definition of the numbers, stating that two classes have the same number if and only if they can be put in 1-1 correspondence ([1884] 1980, 73). What Hume actually wrote is, "When two numbers are so combin'd as that one has always an unite answering to every unite of the other, we pronounce them equal' (Treatise I, iii, I). 'Number' here is taken to mean 'set' or something like it (Tait 1996, 241; Demopoulos 2006, 109), so Hume is merely defining equality, not introducing numbers as objects. Tait (1996) objects to the phrase 'Hume's Principle' in application to infinite sets, since Hume himself disavowed the infinite, but for us, the question of whether, and how univocally, to extend Hume's finitary principle to the infinite is at issue.
} 
In daily life, the collections we reckon about are mostly finite (if conceived as collectionsusually excluding regions of space and the like), and like Anzahl and power, the above principles always agree in such cases. For those not studied in these matters, the two principles are not distinguished at all; they are integral parts of a single concept, which we divide only in post hoc "analysis." Galileo's own inability to separate the two principles is evidence for the unity of this pre-theoretic concept. Though he does implicitly suggest the conflict between them, and thus their distinctness, he never considers the possibility of a notion of size under which one of the principles fails. Both principles appear to have been firmly entrenched in his conception of numerosity, and experience with students shows that the same is true for many today. Such a concept of numerosity, as Galileo showed, cannot be applied to the infinite.

Cantor was wrong in that there is a contradiction when an aggregate and a proper part of it have the same cardinal number, namely the contradiction between the above two principles. Cantor only avoided this by abandoning the first. Of course, he might have meant that there is no contradiction under his technical concept of cardinality, but then to call this cardinal number, in the general sense of numerosity, just ignores the fact that Euclid's Principle was so deeply ingrained in our intuitive notion of (or entrenched beliefs about) numerosity. Furthermore, such a reading would make his next remark about "the non-recognition of this fact" very strange. How could anyone have recognized a fact about his technical concept before he introduced it?

The dogmatic view that Cantor's analysis was right and those of Galileo and Bolzano (the latter discussed below) mistaken is fairly common today, perhaps due in part to Gödel's ([1947] 1983) arguments (also discussed below). ${ }^{21}$ The MCA suggests a more pluralistic res-

\footnotetext{
${ }^{21}$ Frege and Russell were also committed to power as the essential concept of numerosity (Frege [1884] 1980,
} 
olution of the paradox (one that some readers may regard as obvious and standard, but others will disagree). There are at least $t w o$ ways to characterize the relative size of sets, namely Euclid's Principle and Hume's. Euclid's defines what we might call the 'greater' of inclusion: one set is greater $_{\text {inc }}$ than another if it properly includes the other. (This obviously has very limited application, but as we will see, it can be extended.) Hume's suggests the 'greater' of power: one set is greater $_{\text {pow }}$ than another if there is a bijection between latter and a subset of the former, but not between the former and a subset of the latter. Only greater $r_{\text {pow }}$ has generated a rich theory of relative size for arbitrary sets, and only greater ${ }_{\text {pow }}$ concerns the intrinsic size of sets as sets, independent of ordering or any other property imposed on a set or derived from the nature of its elements. Nonetheless, both notions are in some degree legitimate heirs to the pre-theoretic notion of numerosity, in virtue of the entrenchment and seemingly analytic status of our two principles. Cantor's notion of cardinality is not the uniquely right concept, but a particularly elegant and useful one. This pluralistic resolution harmonizes with Cantor's own notion of concept splitting and his professed conceptual libertarianism, yet it is clear from the above quotes, and other considerations below, that this is not how Cantor himself always saw the matter.

I have said Galileo was right that his concept of number did not apply to the infinite, but this does not contradict the conceptual pluralism I am endorsing. Galileo was right about his concept, understood in terms of his tacit commitment to both principles, i.e., his disinclination to consider rejecting one. Further, this was apparently the conception of many, for several before him drew the same conclusion, that 'more' and so on do not apply to the infinite, and few suggested the possibility of a 'more' that violates one of the principles (Duhem [1954] 1985; cf. notes 18, 19 above). Yet, understood in terms of common, explicit conven- 
tions, "the concept" of numerosity was unsettled on the question of whether both principles must be upheld simultaneously in the infinite case. The matter was disputed. (See note 18.) Galileo came rather close to step (1) of the NMMA. He concluded from his paradox that the notion of numerosity simply does not apply to the infinite. It is not that all infinite sets are equal, as he makes clear in the above quote and elsewhere (33). The concept of relative size does not apply at all. One might take this to mean that the question of whether the squares are fewer than the positive integers or not has no determinate answer, but this is not quite right. Galileo gave an answer: "[N]either is the number of squares less than the totality of numbers, nor the latter greater than the former" (32). So for him, the answer to all such questions is 'No' - or perhaps, if we do not read the last quote too closely, 'We cannot speak of such relations among infinities' (31). In any case, a 'yes' is strictly ruled out. If we ask what was the answer according to widely acknowledged, explicit conventions, then there is room for a 'yes' or a 'no,' but Galileo takes the paradox (derived from his tacit principles) to establish a more definite answer.

We can reasonably say that step (2) is present in Galileo's discussion, for he makes the concerns behind his paradox quite clear. The section of the Dialogues in which it appears proposes a notoriously speculative and unsuccessful explanation for the cohesion of bodies: that a solid contains infinitely many miniscule vacua, and it is nature's resistance to these vacua that somehow accounts for the rather strong cohesion of solids. ${ }^{22}$ (He describes an ingenious experiment showing that the force engendered by a single macroscopic vacuum is not enough.) This account presupposes that a solid is composed of infinitely many indivisible parts. But to that there is an old objection (Murdoch 1982), which Simplicio, the Aristotelian

\footnotetext{
${ }^{22}$ The existence of the infinitely many vacua is argued from an ancient relative of the paradox itself, namely the Wheel Paradox of the pseudo-Aristotelian Mechanica.
} 
antagonist in the dialogue, puts in terms of lines rather than solids. If a line is composed of infinitely many parts, then a longer line has an even greater infinity of parts, which seems absurd to the pre-Cantorian. "This assigning to an infinite quantity a value greater than infinity," Simplicio says, "is quite beyond my comprehension” (Galileo [1638] 1954, 31).

Galileo has Salviati reply as follows (anticipating Kant's idea that antinomies arise from stretching our concepts beyond their proper domains):

This is one of the difficulties which arise when we attempt, with our finite minds, to discuss the infinite, assigning to it those properties which we give to the finite and limited; but this I think is wrong, for we cannot speak of infinite quantities as being the one greater or less than or equal to another. To prove this I have in mind an argument... (ibid.)

And here the paradox appears. Hence there is little doubt about its purpose: to show that relative size does not apply to infinite collections, and thus to defeat Simplicio's objection to the particulate analysis of continuous bodies. ${ }^{23}$ More generally, in seeking to escape the line paradox, Galileo was concerned with the puzzling relations between numerosity and geometric magnitude. Thus, what he required from a notion of transfinite numerosity was to illuminate those relations, to determine whether a continuum can coherently be decomposed into infi-

\footnotetext{
${ }^{23}$ One may wonder how one paradox can refute another very similar one, but Galileo's Paradox accomplished this in two ways: First, it showed that the line paradox does not arise from the continuous nature of lines, since Salviati's version concerns the discrete set of whole numbers. Denying the particulate analysis of continua does not resolve the square number paradox, so a more general solution is needed, and Galileo offers one. Secondly, the number paradox provided reason to think that Simplicio's argument was invalid. Salviati's paradox involved two collections, the positive integers and the squares, which very plausibly do exist and which $d o$ consist of infinitely many parts, with much the same puzzling results as the line paradox. If we accept this much (though one might not, instead denying any actual infinity), then an example of the same form, such as the line paradox, cannot show that composition from infinitely many parts is impossible. Neither of these points depends on Galileo's particular way of resolving the square number paradox.
} 
nitely many indivisible parts, and ultimately, to determine whether an infinity of point-vacua can somehow account for the strong cohesion of bodies. As we will see, Bolzano and Cantor too were much interested in the relations between numerosity and magnitude, the nature and structure of continua, and even physical applications.

In effect, Galileo also executed step (3), but with limited success. By declaring that the language of relative size does not apply to the infinite, he was supporting one proposed refinement of the public concept of numerosity. He does not appear to have regarded this as a stipulation; he instead took it to be proved by the paradox, tacitly taking both Euclid's and Hume's Principle for granted. Nonetheless, he asserted a clear boundary where none was publicly established, and which he was therefore free to impose without contradicting any established rules or theory. This did at least partly determine an appropriate reponse to his implicit question whether the squares are fewer than the wholes: either 'No' (for no such relations hold among infinite sets) or, 'That concept does not apply.' However, the bearing of this result on his background motivations was limited. It did imply a kind of degenerate analysis of the relations between magnitude and numerosity, namely that infinite sets have no relations of greater and lesser numerosity, regardless of the magnitudes of the wholes they compose. But this is quite a crude and unenlightening analysis compared to Cantor's, and besides defusing Simplicio's objection, Galileo's solution of the paradox did nothing to clarify the tenability of the analysis of continua into indivisibles, nor the feasibility of Galileo's hypothesis about vacua and cohesion. It was at best a weak partial solution of the larger philosophical problem.

\section{BOLZANO}

Bolzano boldly claimed that infinite sets differed in numerosity, and that transfinite numerosity did not satisfy both Euclid's Principle and Hume's (though again, see note 18). 
He even recognized the divergence of those principles as a necessary and sufficient condition for infinity ([1851] 1950), though he did not, like Dedekind ([1888] 1901), adopt it as a definition. But unlike Cantor, Bolzano saw Euclid's Principle, not Hume's, as indispensible to the notion of quantity. Despite the existence of a bijection between two sets, he claimed, they "can still stand in a relation of inequality in the sense that the one is found to be a whole, and the other a part of that whole" ([1851] 1950, 98). ${ }^{24}$

This he argued from two paradoxes similar to Galileo's, but involving continuous sets. He showed first that the real numbers in the interval $[0,5]$ can be matched with those in $[0,12]$ by means of the equation $5 y=12 x$. Analogously, he exhibited a bijection between the points in a line segment $a c$ and an arbitrary proper segment $a b$, a version of Simplicio's line paradox. In an earlier work ([1837] 1973), Bolzano considered a generalization of Galileo's

\footnotetext{
${ }^{24}$ Berg $(1962,177 ; 1973)$ seems to grant Bolzano deathbed absolution by claiming that Bolzano had renounced his allegiance to Euclid's Principle in his last days. He points out that, in a letter to a pupil dated March 9, 1848, Bolzano retracts the conclusion that $S_{m}$ infinitely exceeds $S_{m+1}$ (see my next paragraph). “Hence,” writes Berg, "it seems that at the last Bolzano confined the doctrine that the whole is greater than its parts to the finite case and accepted [bijection] as a sufficient condition for the identity of powers of infinite sets" (1962, repeated almost verbatim in 1973). But Bolzano's renunciation (published in Bolzano [1837] 1973) is too obscure to establish that he accepted Hume's Principle. In fact, Bolzano continued to deny that principle in the Paradoxes, which he worked on at least until September 30, 1848 (Steele 1950), more than six months after the cited letter. (On the other hand, the quality of the posthumous editing of the Paradoxes has been criticized; see Steele 1950, 54-5.) Furthermore, Bolzano's Paradoxes does treat a variation on Galileo's Paradox in a manner that is apparently consistent with the remarks of his letter (and using similar ' $S_{m}$ ' notation), and yet connects it with lessons learned from the failure of Hume's Principle ([1851] 1950, 115; $c f .100,110,114)$. There Bolzano does not accept the mere existence of a bijection as sufficient for the equinumerosity of infinite sets; only some connection in the "mode of specification or of generation" is sufficient (98). If one sequence is produced from another by squaring each term, for example, then the two sequences have the same number of elements (partly anticipating Gödel's argument discussed below). For Bolzano, this does not contradict Euclid's Principle because he distinguishes between terms that have the same value, so that the result of squaring the terms in the sequence 1 , $2,3, \ldots$ is not a proper subsequence of that sequence. Strange, vague, and problematic as these views are, we have no proof that they cannot be developed into a consistent and interesting theory. Berg's attribution of a Cantorian view to Bolzano looks suspiciously like a symptom of the Cantorian hegemony.
} 
square number paradox (without citing Galileo). To put it in modern terms, he defined the sequences $S_{m}=\left\{n^{2^{m}}\right\}_{n \in \mathbf{Z}^{+}}$for each $m \in \mathbf{N}$ and argued that each $S_{m}$ contains infinitely many more terms than $S_{m+1}$.

Much like Galileo, Bolzano attributed the "air of paradox" (in the continuous examples at least) to the over-extension of notions from the finite case. When a bijection between finite sets is possible, "then indeed are the two finite sets always equal in respect of multiplicity. The illusion is therefore created that this ought to hold when the sets are no longer finite..." (ibid., 98). However, far from concluding that questions of size are vague or indeterminate in the infinite case, or like Galileo, that the notion of size does not apply-far then from initiating our naïve method ${ }^{25}$ - Bolzano regarded it as proved by the so-called paradoxes that bijection does not entail equinumerosity. For Bolzano, being a proper part constituted a notion of 'smaller.' At least twice (pp. 95, 98) he remarked that an infinite set can be greater than another "in the sense that" the two are related as whole to part. ${ }^{26}$

Despite his own view of the matter, Bolzano was in fact free to choose among Euclid's principles. The very fact that he took the paradoxes to refute Hume's Principle in the infinite case is further evidence that before Cantor, Euclid's Principle was integral to tacit conceptions of number, and Hume's was not the uniquely essential principle of numerosity. Indeed, there is a clear sense in which there are more whole numbers than perfect squares, for 'more' often means 'additional.' The whole numbers include the squares and more, i.e., others. A notion of numerosity that does not reflect this would seem to be missing something basic. Even in current mathematics, one sometimes uses "small" in a Bolzanian sense. For

\footnotetext{
${ }^{25}$ Bolzano did, however, attribute certain mistakes in calculating infinite sums to expressions being "devoid of objective reference" ([1851] 1950, 112-114).

${ }^{26}$ But notice also a hint of pluralism: "in the sense that" suggests the possibility of a different sense.
} 
example, a $\sigma$-algebra is often defined as "the smallest" set with certain properties. What is meant in that case is not the set of smallest power (for that does not even pick out a unique set), but rather the unique set, with the specified properties, such that no proper subset has those properties. And even Gödel, in the midst of arguing that Cantor's concepts are forced on us ([1947] 1983), said that new axioms can "increase the number of decidable propositions" (520). But the set of such propositions always has the power of the integers! What Gödel meant by "increase the number" was just to expand the set of decidable propositions to a proper superset of the former-a Bolzanian use of 'number.'

The notion of proper inclusion on its own is not a very satisfying notion of 'greater,' for it leaves vastly many ${ }^{27}$ sets incomparable to each other. However, it is not unreasonable to extend the finitary notion of 'greater' to a merely partial ordering on the infinite sets. This would at least seem to be an improvement on Galileo's strict confinement of relative size to the finite. Furthermore, it is possible to extend any partial ordering to a strict weak ordering ' $<$ ' on the subsets of any well-ordered set, and hence, given the Axiom of Choice, on the subsets of any set (Duggan 1999). In a strict weak ordering, the incomparable sets form equivalence classes, so we can regard any two incomparable sets as equal in "size." We thus obtain a total preorder ' $\leq$ ' that extends both the relation of 'no greater than' on finite sets and the subset relation ' $\subseteq$ '. ${ }^{28}$ Hence we can define notions of smaller, greater, and equal, as broadly as we like, while respecting Euclid's Principle (but abandoning Hume's).

There are two worries about this argument: First, the relations defined might not re-

\footnotetext{
${ }^{27}$ Vastly many, that is, under Cantor's notion of cardinality, and in any case, infinitely many.

${ }^{28}$ We can also choose the extension to be compatible, meaning that if two sets in the old domain (the finite sets) were not of equal size (i.e., if not both $A \leq B$ and $B \leq A$ ), they do not have equal size in the extended relation either (Duggan 1999).
} 
spect other intuitive principles of size, and may thus seem undeserving of that name. For example, let us say a relation ' $<$ ' on sets is monotonic if $A<B$ if and only if $A \backslash B<B \backslash A$ (a generalization of Euclid's Principle). Duggan's powerful extension theorem (1999) shows that for a very broad class of properties, binary relations that have those properties can be extended to totality while preserving the properties. As it happens, monotonicity is not one of the properties covered by Duggan's theorem (since it is not "arc-receptive"), but this in itself does not rule out the possibility that there are total monotonic extensions of the 'less than' and proper subset relations, perhaps in virtue of some other provable extension theorem.

If not, so be it. We already know that no extension of the notion of size preserves every property of size that holds for finite sets. An extension cannot preserve both Hume's Principle and Euclid's. As Cantor wrote, some authors "begin by attributing to the numbers in question all the properties of finite numbers, whereas the infinite numbers, if they are to be thinkable in any form, must constitute quite a new kind of number" (quoted in Jourdain 1915, 74). ${ }^{29}$ If we wish to speak at all about different sizes of infinity, we must choose the properties of size to preserve.

Secondly, we might worry, especially given Duggan's appeal to the Axiom of Choice, that total extensions of the subset relation would be quite arbitrary and uninteresting. But given the power of Duggan's theorem, there may be many possible extensions, and perhaps some among them are especially interesting. In any case, being interesting is a separate concern from being logically possible. I concede that Cantor's notion of cardinal number is probably the most interesting, elegant, intuitively appealing, and useful extension of numerosity to the infinite. I mainly want to insist that such virtues do not make it the uniquely cor-

\footnotetext{
${ }^{29}$ Though Cantor continues anti-pluralistically, "the nature of this new kind of number is dependent on the nature of things and is an object of investigation, but not of our arbitrariness or our prejudice" (ibid.).
} 
rect notion of numerosity in the sense of verisimilitude. Unless we presuppose a semantics in which 'size' automatically designates some particularly eligible property, of which we might have true or false conceptions, the notion of verisimilitude does not apply. So ignoring such semantic considerations, Bolzano was free to choose without risk of being mistaken.

Bolzano did not make the motivations for his Paradoxes ([1851] 1950) explicit, but it is clear that some of them were shared with Galileo. As Cantor noted ([1883b] 1976, 78), the main purpose of the book was to defend the actual infinite, including the constitution of continuous bodies out of point-like atoms, against many apparent contradictions. Bolzano criticized various leaps of logic that others had made, and he took particular interest in divergent infinite sums as well as time. But like Galileo, he also grappled with the curious relations between numerosity and geometric magnitude, defended the analysis of space and matter into a continuum of points, and even attempted to use this analysis to explain physical phenomena.

Bolzano distinguished the magnitude of a spatial extension from the numerosity of the set of points of which it consists ([1851] 1950, 134-5), and then asserted various propositions about magnitude and numerosity, such as that if two figures are perfectly similar, the numbers of their points stand in the same ratio as their geometric magnitudes (136). [He defended this from an objection similar to Simplicio's line paradox, and closer still to the Wheel Paradox, by repeating his rejection of Hume's Principle (137).] Later in the book, he hypothesized that the whole of infinite space was completely filled with substances, and yet various parts were filled with different degrees of density (161). To defend this, Bolzano urged that "there is no sort of impossibility in one and the same (infinite) set of atoms being distributed, now in a larger region without a single point standing solitary there, now in a second and contracted region without a single point requiring to absorb two atoms" (162), and re- 
ferred the reader to his versions of Galileo's Paradox. ${ }^{30}$ Thus, Bolzano was concerned with relations between magnitude and numerosity, the particulate analysis of continua, and physical applications.

Like Galileo, Bolzano took the paradoxes to prove something, but by taking them to prove one thing rather than another, he imposed a conceptual refinement. No doubt he did so with an eye to some of the motivations noted above. But like Galileo's, his success was quite limited. He found many applications for his rather vague conception of infinite numerosity in the Paradoxes, but most seem to have been incoherent and fruitless.

\section{CANTOR}

Cantor's approach to the infinite seems to have been closer to the NMMA than those of Galileo or Bolzano. Though Cantor did not explicitly claim that questions of relative size for infinite sets lacked uniquely right answers, he was somewhat pluralistic about concepts of transfinite number, and as I will explain, this suggests that even for him, some questions about relative numerosity were indeterminate until refined. Furthermore, he did, unlike Galileo and Bolzano, regard himself as extending the concept of number, and he did so under the influence of certain specific motives.

By 1887, Cantor clearly endorsed multiple notions of number, including power and Anzahl (by then taking the additional names of cardinal and ordinal number), as well as the more general notion of order type ([1887-8] 1962). It is often thought that power was always the primary notion of number for Cantor (e.g., Ferreirós 1999, 265, 270), who did make sev-

\footnotetext{
${ }^{30}$ The point of referring to the paradoxes was apparently to show that a continuum of atoms, with no gaps, could nonetheless be compressed into a smaller region, increasing its density. But this seems incompatible with his assertion that the ratio between numbers of elements equals the ratio between magnitudes.
} 
eral remarks about the basic, general, and intrinsic character of power, ([1882] 1962, 150; Grattan-Guinness 1970, 86). Ferreirós points to those remarks as well as the structure of Cantor's "most mature work," the Beiträge ([1895-7] 1915), in which the cardinals are introduced before the ordinals. But the remarks in question leave some room for interpretation and are counteracted by others. In fact, it was Anzahl that Cantor first called the "number of elements" of an infinite set, ${ }^{31}$ in the Grundlagen, while power retained its less suggestive moniker for some time. ${ }^{32}$ Even in the Beiträge, to which Ferreirós appeals, Cantor exalted the notion of order type. That concept, he wrote,

...embraces, in conjunction with the concept of 'cardinal number' or 'power' introduced in Section 1, everything capable of being numbered that is thinkable, and in this sense cannot be further generalized. It contains nothing arbitrary, but is the natural extension of the concept of number. (117)

\footnotetext{
31 "In the case of infinite aggregates, on the other hand, absolutely nothing has so far been said, either in my own papers or elsewhere, concerning a precisely defined number of their elements [Anzahl der Elemente]" (Cantor [1883] 1976, 71; 1962, 167). But soon, “Another great gain...is a new concept not previously in existence, the concept of the number of elements [Anzahl der Elemente] of a well-ordered infinite manifold ([1883] 1976, 71; 1962, 168). However one translates 'Anzahl' here, 'Anzahl der Elemente' strongly suggests a notion of numerosity rather than position in a series.

${ }^{32}$ His first use of 'cardinal number' in print appeared in 1887 ([1887-8] 1962). Jourdain (1915) quotes Cantor using it in a lecture of 1883, and a footnote from Cantor attributes the relevant part of [1887-8] 1962 to a lecture of that year and a letter of 1884 (p. 387). Strangely, though, Cantor did not to my knowledge use 'cardinal' in any publications or other letters before 1887. Even in his review of Frege's Grundlagen (Cantor [1885] 1962) and his 1886, Cantor used 'ordinal number' but not 'cardinal,' and kept power distinctly separate from number [even though Frege had argued (using different words) that Cantor's Anzahlen were ordinal numbers and his powers were cardinals ([1884] 1980, 98).] It seems plausible, then, that Cantor only inserted the phrase 'cardinal number' into the later published form of his lecture (and perhaps likewise for the 1885 letter published as part VIII of [1887-8] 1962). Jourdain may have used 'cardinal number' anachronistically, as many authors do. believing that Cantor always thought of power as the fundamental notion of numerosity. If so, the cardinal/ordinal terminology was probably spurred by Frege's remarks and further justified by Cantor's development of cardinal arithmetic. (See note 37.)
} 
Power, then, was not unequivocally privileged, for Cantor. The best we could say for it in light of this quote is that it was somehow "conjoined," to or within, the natural extension of number. The pluralism here, encompassing at least power and order type, is explicit.

Still, one might infer from Cantor's "ordinal/cardinal" terminology that power was his only concept of numerosity. He even wrote, "The 'powers' represent the unique and necessary generalization of the finite "cardinal numbers"” ([1891] 1996, 922). But as we have just seen, it was the Anzahlen that first took that position. In the Grundlagen, Cantor made it clear that he regarded Anzahl as a notion of numerosity, relativized to an ordering:

[A] finite aggregate exhibits the same number of elements [Anzahl von Elementen] ${ }^{33}$ for every order of succession that can be given to its elements; on the other hand, different numbers [Anzahlen] will in general have to be attributed to aggregates consisting of infinitely many elements, depending upon the order of succession given to the elements" ([1883] 1976, 72; 1962, 168).

This was natural, given the way in which the Anzahlen emerged from Cantor's theory of point sets. As is well documented (Jourdain 1915), they sprang from the indexes on his "derived sets" $P^{(v)}$, where $P^{\prime}=P^{(1)}$ is the set of limit points of a set $P$, and $P^{(v+1)}=P^{(v) \prime}(1872)$. Cantor later defined $P^{(\infty)}$ as the intersection of all derived sets $P^{(v)}$ for $v$ a positive integer ([1880] 1962). Intuitively, $P^{(\infty)}$ was the result of taking the derivative infinitely many times (once for every positive integer) and $P^{(\infty+v)}$ the result of taking it $v$ more times. This helps explain how the Anzahlen represented a kind of numerosity; they answered the question, "How many times?"

Hence there was some pluralism in Cantor's conception of numerosity. Already in

\footnotetext{
${ }^{33}$ Again, this expression strongly suggest numerosity.
} 
the Grundlagen, the claim that the original concept of number splits in two implied that both power and Anzahl were in some degree legitimate heirs to the title of 'number.' Such pluralism suggests that even for Cantor, certain questions about the relative size of infinite sets were indeterminate prior to his refinements. Consider the ordered set $(1,4,9,16, \ldots ; 2,3,5$, 6...), i.e., the positive integers arranged so that the squares come first. Is this ordered set bigger than its infinite initial segment $(1,4,9, \ldots)$ ? With respect to Anzahl, yes: The former sequence has the ordinal $2 \omega$, while the latter has ordinal $\omega$. But with respect to power, no. Hence, the question requires refinement. In fact, even the question of the Anzahl alone may be indeterminate, for it depends on the ordering that we apply to a set. In particular, Galileo's question whether the squares are fewer than the positive integers may be seen as indeterminate, even rejecting Euclid's Principle, provided that 'fewer' can be understood in terms of Anzahl and one does not take the natural orderings for granted. Thus, Cantor's own ideas implied that some questions of relative size, and by a stretch even Galileo's, were insufficiently precise to determine an answer.

However, Cantor's pluralism and libertarianism did not extend to Euclid's Principle. We have already noted his claim that there is simply no contradiction when a set has the same cardinality as a proper subset. As well, the Beiträge contained a venomous assault ([1895-7] 1915; 117-118) on Veronese's definition of equality, which attempted a compromise between Euclid's Principle and Cantor's Anzahlen: "Numbers whose units correspond to one another uniquely and in the same order and of which the one is neither a part of the other nor equal to a part of the other are equal" (quoted in Cantor, ibid.). ${ }^{34}$ Cantor criticized the circularity of this definition (ibid.), but according to Dauben $(1979,234)$ he also objected to its arbitrari-

\footnotetext{
${ }^{34}$ Veronese's work is now regarded as an important forerunner to that of Robinson, Conway, and Ehrlich, the latter two of which generalize Cantor's transfinite numbers (Ehrlich 2006).
} 
ness. "He complained to Peano that Veronese believed the definition of equality, both for numbers and for order types, was entirely at the mercy of one's choice, which was a heretical suggestion from Cantor's point of view..." (ibid.) On Dauben's reading, Cantor was much more the dogmatic essentialist than the Grundlagen's libertarian declarations would suggest.

Hence, Cantor might appear to have been inconsistent on the subject of mathematical freedom. In the Grundlagen he defended the actual infinite both by waxing grandiloquent on the freedom of mathematics and by claiming that his theory was forced on him ([1883b] 1976, 75). But perhaps he can be seen as occupying a coherent middle ground: He was forced to recognize certain extensions of the notion of number, he might have said, but not to forsake all others. The forcing he refers to is best understood in terms of his derived point sets. Taking repeated derivatives and infinitary unions, Cantor obtained sets with larger and larger transfinite indices, a process he called "necessary" and "free from any arbitrariness" ([1880] 1962, 148). Without these indices, many of his future results on point sets would have been unattainable, including the Cantor-Bendixson Theorem (1884a) and the important theorem that any set with a countable $\alpha^{\text {th }}$ derivative, for any Anzahl $\alpha$, has zero outer content (the lower limit of the total length of any set of covering intervals), and hence, in modern terms, zero measure (1883a). Considered independently of point sets, the Anzahlen enabled Cantor to establish an infinite hierarchy of infinite powers, having only established two infinite powers before, and to show that there is a unique second infinite power, seemingly a step toward Cantor's goal of proving the Continuum Hypothesis. Thus Cantor was forced to recognize the Anzahlen by their apparent naturalness and his need to employ them, but none of this required him to dismiss other notions of transfinite number. After all, he later incorporated power and order type as additional concepts of number (1887; [1895-7] 1915). ${ }^{35}$

\footnotetext{
${ }^{35}$ It is not clear, then, why Cantor categorically rejected Euclid's Principle. Surely it was in part because the
} 
Moreover, Cantor called Anzahl and order type extensions of the concept of number ([1883b] 1976; ([1895-7] 1915), not mere descriptions of its transfinite implications. He even called Anzahl "a new concept not previously in existence” ([1883b] 1976, 71, Cantor's emphasis) and pointed out that any transfinite number must be "quite a new kind of number" (Jourdain 1915, 74). Hence he did not see himself, like Galileo and Bolzano, as merely deducing facts about the sizes of transfinite sets from a well established notion of number, but as defining new concepts. If he did not regard this as mere stipulation, it can only be because he thought that some concepts were coherent and counted as concepts of number, while others, not. But that much is perfectly consistent with the NMMA.

If we take Cantor's words seriously, then, we must conclude that he saw see himself as extending the concept of number, and with some degree of freedom. Further, he did so in light of some explicitly acknowledged motivations. He cited a need to employ the Anzahlen in the theory of point sets as well as some applications to function theory ([1883b] 1976). But he also stated goals in philosophy and natural science that help to explain his interest in both the Anzahlen and the powers, namely the resolution of certain difficulties in the philosophical systems of Leibniz and Spinoza, which he thought would help us to develop a rigorous and "organic" account of nature. The standard account of Cantor's motives largely ig-

Euclidean notions of number on offer, such as Bolzano's and Veronese's, seemed incoherent. But one is also led to speculate that Cantor's bouts of dogmatism were partly because of his vitriolic debate with Veronese over the coherence of infinitesimals. [The opposite has been suggested, i.e., that Cantor opposed Veronese because he was dogmatic about his concept of number, but Cantor vehemently denied infinitesimals as early as 1878 (Ewald 1996, 867), well before introducing his transfinite numbers.]

It is worth noting too that Cantor's Anzahlen made some concessions to Euclid's Principle. Not every proper part of a well ordered set has smaller Anzahl than the whole, but every proper initial segment does. The Anzahlen thus partly reflect the idea, encoded in Euclid's Principle, that if we add more elements to an infinite set, we have a larger set, though for Anzahlen this only holds if the new elements are added at (or sufficiently near) the end of a sequence. 
nores these remarks and places his main motives within mainstream function theory (e.g., Jourdain 1906-13; 1915; Dauben 1979). However, Ferreirós (2004) makes a strong case that Cantor was not chiefly concerned with mainstream mathematics but with broad biological, physical, and even spiritual matters. Cantor is quite explicit about this in an 1884 letter:

I have been working on this project of a precise deepening into the essence of everything organic for 14 years already. It constitutes the real motivation why I have confronted, and during this time have never lost sight of, the fatiguing enterprise of investigating point-sets, which promises little recognition. (Ferreirós 2004)

Through the background of German Romantic Naturphilosophie and Cantor's own testimony, Ferreirós shows that by "organic" Cantor did not simply mean biological; rather he sought a natural philosophy unifying mechanistic and spiritual elements.

Cantor's work on this program raised key mathematical goals for his theory of the transfinite, namely to illuminate what we now call the topological and measure-theoretic features of physical space and objects. For example, he proposed an analysis of matter into a countable infinity of point-like corporeal "monads" and a continuum of point-like ethereal monads, and used his theorems on point sets, power, continuity, and outer content to offer explanations of various physical phenomena (Ferreirós 2004). Thus Cantor's investigation of the transfinite was in considerable part motivated by an interest in the qualitative structural features of space and matter. In particular, he shared with Galileo and Bolzano an interest in the relations between numerosity and geometric magnitude (addressed by Cantor in terms of dimension and outer content), the analysis of matter into a continuum of points, and the application of this analysis to explain physical phenomena.

Cantor did not deliberately design his concept of cardinal number to serve those goals, but that concept developed very gradually under their influence, each conceptual develop- 
ment being spurred by new applications and results. Cantor took up questions about bijection even before 1869 (Ferreirós 2004, 52), long before arriving at the notions of power, countability, and last of all cardinal number. Soon after he raised the question of a bijection between the whole numbers and the reals, in an 1873 letter to Dedekind, he wrote, "[I]t has no special practical interest for me. And I entirely agree with you when you say that for this reason it does not deserve much effort" (Ewald 1996, 844). Yet an answer, he pointed out, would yield a new proof of the existence and density of the transcendental numbers, and once Cantor accomplished that, Dedekind remarked that this proved the problem was interesting and worthy of effort (ibid., 848). In 1877 Cantor developed the proof that there is a bijection between a line segment and any $n$-dimensional continuum, and simultaneously began using the word 'power' (Ewald 1996, 853ff.). In the publication of that result (1878), he even defined the notions of smaller and larger powers, and pointed out the fact that the even numbers have the same power as the positive integers. The term 'countable' or 'denumerable' did not appear until 1882, when Cantor proved that, in modern terms, an $n$-dimensional space can include at most countably many disjoint open sets ([1882] 1962). At that time, only sets of the first two infinite powers were known. Only after using the ordinals to generate an infinite hierarchy of powers and producing several more theorems on the powers of point sets (including that countable sets have zero content; 1883a) did Cantor adopt the term 'cardinal number' ([1887-8] 1962, from a lecture of late 1883 - but see note 34 above). ${ }^{36}$ Thus his

\footnotetext{
${ }^{36}$ Apparently, Cantor had also worked out cardinal arithmetic in a manuscript of 1885 . Jourdain $(1915,79)$ reports this, but perhaps based on Cantor's footnote in [1887-88] 1932 (411), which is in fact a bit vague ("[E]r ist der Hauptsache nach vor bald drei Jahren verfaßt..."). In any case, if Cantor did develop cardinal arithmetic before or simultaneously with adopting the term 'cardinal number' (also contrary to Jourdain; see note 34), then this would further explain Cantor's construal of power as cardinal number, for, one justification he gave for calling his ordinals by the name 'number' was their possession of a systematic arithmetic (in an 1882 letter; Ewald 1996, 876).
} 
concept of cardinal number evolved, in a dialectical milieu of applications and innovations, most of which concerned the structure of continuous spaces and point sets within them. If Cantor did not deliberately design the concept to shed light on such matters, those interests nonetheless seem to have exerted a selection pressure on the concept's evolution. In this respect the concept was tooled to fit its motivations.

The result was tremendously successful. Cantor's physical hypotheses were as speculative and mistaken as Galileo's infinity of point-vacua and Bolzano's smooth plenum of variable density, but still, his theory of transfinite numerosity was much more fruitful than those of Galileo and Bolzano concerning all three of the shared motivations we have identified. Not only did Cantor offer a way out of objections to the particulate analysis of the continuum, such as the supposedly absurd consequence that one obtains infinities of different sizes—all three thinkers managed that—but he also initiated a rich and ultimately coherent theory of such sizes which shed further light on the structure of continua. He was able to show that while there are different sizes of infinity (powers and order types), line segments of different lengths have the same power ${ }^{37}$, and if both segments are closed, the same order type (a consequence of [1895-7] 1915, 134), contrary to Simplicio's argument (Galileo [1638] 1954, 31). Thus he was able to distinguish clearly between geometric magnitude and "number of elements." He further showed that continua of different dimensions have the same power (1878), and that finite and countable point sets have zero magnitude ([1882] 1962). And though his own speculations on the structure of matter failed, his theory of the transfinite has in fact afforded some insight into physical phenomena.

The fact that countable sets have measure zero has been especially useful in this re-

\footnotetext{
${ }^{37}$ In effect, Bolzano showed this too, but he did not have the notion of power, i.e., of an equivalence class induced by bijection, and he did not take a bijection between sets to show anything significant ([1851] 1950).
} 
gard. Given a measure-zero set of possible states for some physical system, it is generally plausible to assume that the probability of the system taking on one of those states at a given time is zero. [Poincaré made much use of this assumption in his celestial mechanics ([189299] 1957), and it plays a key role in statistical mechanics (Sklar 1993).] The same, then, goes for countable sets of states. In one interesting application, Hadamard (1898) showed that, of the continuum-many bounded geodesics through a given point on a surface of negative curvature, only countably many are asymptotic to closed curves. Hence, "almost all" bounded curves on such a surface—with regard to power, measure, and frequency—are thoroughly non-periodic, and this is reflected in the typically chaotic behavior of many dynamical systems. Thus power sheds light on physical phenomena.

I say that such results - those concerning the structure of continua, the relations between numerosity and magnitude, and physical phenomena-are good reasons to regard Cantor's theory of the transfinite as successful relative to the goals that he shared with Galileo and Bolzano. Whether this accounts for the popular success of his theory is another question. No doubt the fact that countable sets have zero measure largely explains the introduction of Cantor's cardinals in many elementary analysis texts, and this in turn must have contributed to their widespread acceptance. Other contributing factors likely include applications of both power and Anzahl in function theory and analysis (Cantor [1884b] 1962, 260; Mittag-Leffler 1884; Borel 1895; cf. Hallett 1979), the support of Weierstrass, Mittag-Leffler and Hilbert (Dauben [1993] 2004; Hilbert [1900] 1902; 1926), Frege and Russell's use of power in their definitions of number (Frege [1884] 1980; [1893-1903] 1962; Russell [1903] 1992), Frege's proof of the axioms of arithmetic from Hume's Principle ([1893-1903] 1962; cf. Hale and Wright 2001), and perhaps most of all, the intrinsic nature of power, the fact that it is independent of the nature and ordering of elements (a point emphasized by both Frege [1884] and Russell [1903] 1992). No doubt the last two points are strong reasons to count Cantor's 
theory a genuine success, popularity aside, but this is true relative to certain goals, and not the ones we have identified as common to our three historical figures.

To summarize the essential points we have noted about Cantor's theory, (1) Cantor was pluralistic about concepts of numerosity, within limits; (2) such pluralism implied indeterminacy in some questions about numerosity; (3) Cantor explicitly stated certain philosophical and scientific motivations; (4) each of the three common goals we have attributed to Galileo and Bolzano was either included in or raised by Cantor's explicit motivations; (5) Cantor did devise new concepts of numerosity, though he did not regard them as entirely free inventions; (6) he did so gradually, while discovering applications and results that apparently influenced the theory; and (7) the resulting concepts proved to be very useful for the common goals we have identified.

\section{GÖDEL}

The NMMA (Section I) takes it for granted that we can identify questions that lack a determinate answer, and that we are free to extend and refine concepts and meanings as we wish. Yet some metaphysicians hold that certain questions, whose answers surely seem indeterminate, nonetheless have unique factual answers (Lewis 1984, 1985; Sider 2001 and forthcoming; Olson 2006). One might think that the reference of numerosity expressions was likewise predetermined, before Cantor's work, in such a way that any extension of the number concept that produced different results would be not only inapt but false. Gödel's view was close to this ([1947] 1983). He claimed that Cantor's concept of cardinality as well as the axioms of set theory had a self-evident truth that we cannot help but recognize, if we carefully examine the concepts that we already loosely grasp. But in arguing that such ideas are forced upon us, Gödel neglects the fact that they are over-determined. With the concept of numerosity as with our other intuitions about sets, the very principles that once seemed unde- 
niable have led to paradoxes, including Galileo's, and cannot be maintained. Gödel (op. cit.) had an excuse for the other paradoxes of set theory: they result from misapplying the intuitive principles to exotic, impossibly comprehensive collections, such as the set of all sets. If we admit only sets of pre-established objects (the iterative conception of set), the paradoxes do not arise. But this is not so for Galileo's Paradox; that problem lives right in our back yard, among the whole numbers. If we want to have any notion of transfinite numerosity we must face up to it and adopt a notion (or several) that violates either Euclid's Principle or Hume's (or both).

Admittedly, Gödel gives a very compelling argument for Hume's Principle: If two sets can be put in one-to-one correspondence, then we could conceivably alter the individual elements of one set until they were indistinguishable from their counterparts in the other, and then surely the two sets must have the same numerosity. I say this is very compelling, but nonetheless it is only an intuition pump. Gödel disregards the fact that Euclid's Principle is also intuitively compelling! If set $A$ contains everything that is in set $B$ and also some further things, then it contains more. Both Euclid's and Hume's Principles seem forced on us. To have a consistent theory of transfinite numerosity, we must break free of these forces, much as Gauss and Lobachevsky broke free of the parallel postulate. We have learned from them that intuitions do not limit our freedom to form counterintuitive conceptions. Even if Hume's Principle seems stronger than Euclid's, no adequate reason has been given to believe that it is unrevisable or a brute fact. It is up to us to choose our preferred principles, or to articulate an arsenal of different concepts incorporating different principles.

On the other hand, Gödel's realism might supply a reason to regard a conception as false. If one concept satisfying some of our intuitions has an ontological status privileged over others, we might therefore regard that concept as the one that we had loosely grasped all along. In other words, some special "existence" (or some other property) beyond mere 
consistency might make one concept more eligible than others. If such eligibility helps to determine reference, then there might be a fact about which transfinite relation is really the referent of 'more' and other such terms. Again, it seems wisest to ignore such considerations and focus on the motivations for a concept; never mind what the referent of the pre-theoretic term is, let us establish new concepts that bake some bread. But now we may worry that we cannot even do that; the "real" objects may be so much more eligible in virtue of their "reality" that we cannot force our words to mean anything else.

The usual objection to Gödel's realism is that it makes our possession of mathematical knowledge inexplicable (Benacerraf [1973] 1983; cf. Maddy 1996; 1997). Gödel proposes a special faculty of mathematical perception, but since abstract objects lack causal efficacy, such a faculty seems impossible. The objection I have raised just above gives us further reason for doubt: The fact that our intuitions sometimes lead us into paradox suggests that we have no trustworthy mathematical perception. Why then should we suppose that such "perception" is anything but prejudice?

A standard alternative to Gödel's form of realism is the indispensability argument. In Quinian terms, it says that if we accept a theory, we are committed to the objects over which its quantifiers range. Insofar as our best empirical theories involve quantification over mathematical objects, we should accept that those objects exist (Quine [1948] 1953; Putnam $1971 ; 1975 b)$. However, this faces charges of contradicting mathematical practice, for mathematicians believe in many things that have not yet proven useful (Maddy 1997, 106-7, 153-160 ). Maddy (1997) instead proposes that we take mathematical considerations and motivations, such as the desire to provide a universal foundation for all of mathematics, as the arbiters of mathematical truth. Quine's and Maddy's views do not seem to give us reason to deny the existence of other objects besides those that serve empirical and mathematical 
goals, ${ }^{38}$ but we might worry that scientific usefulness itself implies a strong eligibility that prevents us referring to other things.

But suppose there are indeed irresistible mathematical reference magnets. How might that affect mathematical practice? Can we not still give alternative definitions and theories, and follow out their consequences? Even if we do not succeed in referring to the things we wish to, this has no impact on what we can logically deduce. Hence it again seems that all that is important about a concept or theory, beyond consistency, is its interest and fruitfulness.

\section{CONCLUSIONS}

It has been claimed here that at least some genuinely philosophical problems are solvable by the Method of Conceptual Articulation, and some have already been solved by such means. In particular, Galileo's Paradox was resolved by the articulation of numerosity into distinct concepts, including those of proper inclusion, Anzahl, and power. Granted, none of our historical figures saw themselves as stipulating extensions of the concept of number with complete freedom. Cantor in particular seemed to recognize that he was presenting genuine extensions, but not arbitrarily; he regarded his multiple conceptions as forced by his mathematical needs, by the determinate iterative process that defined the ordinals, and by considerations of naturalness. But new extensions they were nonetheless.

Power has become the basis of an elegant and useful theory and has proven especially useful in addressing the motivations common to Galileo, Bolzano and Cantor, namely, to

\footnotetext{
${ }^{38}$ Gödel of course has argued from his theorems on the incompleteness of arithmetic that there is more to mathematical truth than mere consistency. But even if we agree with Gödel that there is a unique system of whole numbers - a unique intended model for our axioms of arithmetic — that is no reason to deny the existence of other objects, of non-standard models of arithmetic. Indeed, their existence is implied by the incompleteness theorems and the completeness of first-order predicate logic.
} 
grasp the relations between numerosity and geometric magnitude, to defend the analysis of the continuum into points, and to explain physical phenomena. It is in virtue of its success in serving such motivations that Cantor's theory of transfinite numbers constitutes a solution to some of the deeper philosophical problems posed by Galileo's Paradox.

Nonetheless, to say that power is the only correct notion of numerosity is distorting. Anzahl too can be considered as a notion of numerosity, and Cantor did so conceive it. Furthermore, order extension theorems like Duggan's give us reason to think that a theory of numerosity satisfying Euclid's Principle is possible.

In its naïve form, the Method of Conceptual Articulation presupposed that empty questions could be identified and concepts freely refined or modified. These presuppositions face many challenges, perhaps most forcefully from externalist theories of reference. But those challenges do not bear on the most important elements of the method. However reference works, and whether or not we can distinguish between determinate and indeterminate questions, we can still, at least sometimes, identify background motivations for our philosophical puzzles, if perhaps after the fact, and we can articulate concepts, or theories if you prefer, that serve to address those motivations.

\section{REFERENCES}

Ackerman, Felicia. 1994. Roots and consequences of vagueness. Philosophical Perspectives 8: 129136.

Alston, W. P. 1964. Philosophy of Language. Englewood Cliffs: Prentice-Hall.

Ambrose, Alice. 1959. Proof and the theorem proved. Mind 68: 435-445.

Berg, Jan. 1962. Bolzano's Logic. Stockholm: Almquist \& Wiksell.

---- . 1973. Introduction. In Bolzano [1837] 1973, 1-30.

Benacerraf, Paul. [1973] 1983. Mathematical truth. Journal of Philosophy 70: 661-80. Reprinted in Bencacerraf and Putnam 1983, 403-420.

Benacerraf, Paul, and Hilary Putnam, eds. 1983. Philosophy of Mathematics: Selected readings; Second edition. Cambridge: Cambridge University Press. 
Bolzano, Bernard. [1837] 1973. Theory of Science. Translated by Burnham Terrell, ed. Jan Berg. Dordrecht: D. Reidel Publishing.

---- . [1851] 1950. Paradoxes of the Infinite. Translated by F. Prihonsky. London: Routledge.

Borel, Emil. 1895. Sur quelques points de la théorie des fonctions. Annales Scientifiques de l'Ecole Normale Supérieure 12: 9-55.

Buzaglo, Meir. 2002. The Logic of Concept Expansion. Cambridge: Cambridge University Press.

Cantor, Georg. 1872. Über die Ausdehnung eines Satzes aus der Theorie der Trigonometrischen Reihen. Mathematische Annalen 5: 123-132.

---- . 1874. Über eine Eigenschaft des Inbegriffes aller reelen algebraischen Zahlen. Journal für die reine und angewndte Mathematik 77: 258-262.

----- . 1878. Ein Beitrag zur Mannigfaltigkeitslehre. Journal für die reine und angewndte Mathematik 84: 242-258.

---- . [1880] 1962. Über unendliche, lineare Punktmannigfaltigkeiten, 2. Mathematische Annalen 17: 355-358. Reprinted in Cantor 1962, 145-148.

---- . [1882] 1962. Über unendliche, lineare Punktmannigfaltigkeiten, 3. Mathematische Annalen 20: 113-121. Reprinted in Cantor 1962, 149-157.

---- . 1883a. Über unendliche, lineare Punktmannigfaltigkeiten, 4. Mathematische Annalen 21: 51-58.

----- . [1883b] 1976. Grundlagen einer Allgemeinen Mannigfaltigkeitslehre. Translated by Uwe Parpart, The Campaigner 9: 69-97.

----- . 1884a. Über unendliche, lineare Punktmannigfaltigkeiten, 6. Mathematische Annalen 23: 453488.

---- . [1884b] 1962. De la puissance des ensembles parfaits de points. Acta Mathematica 4: 381-392. Reprinted in Cantor 1962, 252-260.

---- . [1885] 1962. Die Grundlagen der Arithmetik. Deutsche Literaturzeitung 6: 728-729. Reprinted in Cantor 1962, 440-441.

----- . 1886. Über die verschiedenen Standpunkte in bezug auf das aktuale Unendliche. Zeitschrift für Philosophie und philosophiche Kritik 88: 224-233.

----- . [1887-8] 1962. Mitteilungen zur Lehre vom Transfiniten, I, II. Zeitschrift für Philosophie und philosophiche Kritik 91: 81-125. Reprinted in Cantor 1962, 378-396.

---- . [1891] 1966. Über eine elementare Frage der Mannigfaltigkeitslehre. Jahresbericht der Deutschen Mathematiker-Vereingung 1: 75-78. Translated in Ewald 1996, 920-922.

---- . [1895-7] 1915. Contributions to the Founding of the Theory of Transfinite Numbers. Translated by Philip E. B. Jourdain. New York: Dover.

----- . 1962. Gesammelte Abhandlungen: Mathematischen und Philosophischen Inhalts. Ernst Zermelo, ed. Hildesheim, Germany: Georg Olms Verlagsbuchandlung.

Carnap, Rudolph. 1950. Empiricism, Semantics, and Ontology. Revue Internationale de Philosophie 
4: $20-40$.

Dauben, Joseph W. 1990. Georg Cantor: His Mathematics and Philosophy of the Infinite. Princeton: Princeton University Press.

---- . [1993] 2004. Georg Cantor and the battle for transfinite set theory. Proceedings of the ACMS. Published on line in Journal of the ACMS 2004: http://www.acmsonline.org/journal2004.html. Dedekind, Richard. [1888] 1901. The nature and meaning of numbers. In Essays on the Theory of Numbers. Translated by Wooster Woodruff Beeman. Chicago: Open Court Publishing Company, $31-115$.

Demopoulos, William. 2006. The neo-Fregean program in the philosophy of arithmetic. In Emiuly Carson and Renate Huber, eds., Intuition and the Axiomatic Method. Dordrecht: Springer.

DiSalle, Robert. 2002. Newton's philosophical analysis of space and time. In Cohen, I. Bernard, and George E. Smith, eds., The Cambridge Companion to Newton. Cambridge: Cambridge University Press.

----- . 2006. Understanding Spacetime: The Philosophical Development of Physics from Newton to Einstein. Cambridge: Cambridge University Press.

Duggan, John. 1999. A General Extension Theorem for Binary Relations. Journal of Economic Theory 86: 1-16.

Duhem, Pierre. [1954] 1985. Medieval Cosmology: Theories of Infinity, Place, Time, Void, and the Plurality of Worlds. Chicago: University of Chicago Press. (Excerpts from Duhem's Système du monde, Part V, first published 1954-59.)

Ehrlich, Philip. 2006. The rise of non-Archimedean mathematics and the roots of a misconception I: The emergence of non-Archimedean systems of magnitudes. Archive for the History of the Exact Sciences 60: 1-121.

Ewald, William, ed. 1996. From Kant to Hilbert: A Source Book in the Foundations of Mathematics, Vol. II. Oxford: Clarendon Press.

Ferreirós, José. 1999. Labyrinth of Thought: A History of Set Theory and its Role in Modern Mathematics. Basel: Birkhäuser Verlag.

---- . 2004. The motives behind Cantor's set theory—physical, biological, and philosophical questions. Science in Context 17: 49-83.

Frege, Gottlob. [1884] 1980. The Foundations of Arithmetic. Translated by J.L. Austin. Evanston, Illinois: Northwestern University Press.

---- . [1893-1903] 1962. Grundgesetze der Arithmetik, Vols. I, II. Hildesheim, Germany: Georg Olms.

Galileo Galilei. [1638] 1954. Dialogues concerning two new sciences. Translated by Henry Crew and Alfonso de Salvio. New York: Dover.

Gardies, Jean-Louis. 1984. Pascal entre Eudoxe et Cantor. Paris: Librarie Philosophique J. Vrin. Gödel, Kurt. [1947] 1983. What is Cantor's Continuum Problem? The American Mathematical 
Monthly, 54: 515-525. Reprinted in Benacerraf and Putnam 1983, 470-485.

Gratan-Guinness, Ivor. 1970. An unpublished paper by Georg Cantor: Principien einer Theorie der Ordnungstypen, erste Mitteilung. Acta Mathematica 124: 65-107.

Hadamard, Jacques. 1898. Les surfaces à courbures opposées et leurs lignes géodésiques. Journal de Mathématiques Pures et Appliquées 4: 27-73.

Hale, Bob, and Crispin Wright. 2001. The Reason's Proper Study: Essays Towards a Neo-Fregean Philosophy of Mathematics. Oxford: Oxford University Press.

Hallett, Michael. 1979. Towards a theory of mathematical research programs I, II. British Journal for the Philosophy of Science 30: 1-25, 135-159.

Hempel, Carl Gustav. 1950. Problems and changes in the empiricist criterion of meaning. Revue Internationale de Philosophie 41: 41-63.

Hilbert, David. [1900] 1902. Mathematische probleme. Göttinger Nachrichten 1900: 253-297. Translated in Bulletin of the American Mathematical Society 8 (1902): 437-479.

----- . 1926. Über das Unendliche. Mathematische Annalen 95: 161-190.

Hodes, Harold T. 1984. Logicism and the ontological commitments of arithmetic. Journal of Philosophy 81: 123-149.

Jourdain, Philip E. B. 1906-13. The development of the theory of transfinite numbers. Archiv der Mathematik und Physik x: 254-281; xiv: 289-311; xvi: 21-43; xxii: 1-21.

----- . 1915. Introduction. In Cantor [1895-7] 1915, 1-82.

Kant, Immanuel. [1781] 1965. Critique of Pure Reason. Translated by Norman Kemp Smith. New York: St. Martin's Press.

Kripke, Saul. 1971. Identity and Necessity. In Identity and Individuation, ed. Milton K Munitz. New York: New York University Press, 135-164.

---- . 1972. Naming and Necessity. Oxford: Blackwell.

Lewis, David. 1983. New work for a theory of universals. Australasian Journal of Philosophy 61: 343-77.

---- . 1984. Putnam's paradox. Australasian Journal of Philosophy 62: 221-36.

Maddy, Penelope. 1993. Does V = L? Journal of Symbolic Logic 58: 15-41.

---- . 1996. The legacy of "Mathematical Truth." In A. Morton and S. Stich, eds., Benacerraf and his Critics. Oxford: Basil Blackwell, 60-82.

---- . 1997. Naturalism in Mathematics. Oxford: Oxford University Press.

Mittag-Leffler, Gosta. Sur la representation analytique des fonctions d'une variable indépendenante. Acta Mathematica 4: 1-79.

Murdoch, John E. 1982. Infinity and continuity. In Norman Kretzmann, Anthony Kenny, and Jan Pinborg, eds., The Cambridge History of Later Medieval Philosophy. Cambridge: Cambridge University Press, 564-591. 
Myrvold, Wayne. 1997. The decision problem for entanglement. In Potentiality, Entanglement, and Passion-at-a-Distance, eds. R. S. Cohen et al., 177-190. Great Britain: Kluwer Academic Publishers.

Olson, Eric T. 2006. Imperfect identity. Proceedings of the Aristotelian Society, 106 (2): 247-264.

Parfit, Derek. 1971. Personal Identity. The Philosophical Review 80 (1): 3-27.

---- . 1984. Reasons and Persons. Oxford: Clarendon.

Parker, Matthew W. 2003. Undecidability in $\mathbf{R}^{n}$ : Riddled basins, the KAM tori, and the stability of the solar system. Philosophy of Science 70: 359-382.

----- . 2005. Undecidable long-term behavior in classical physics: Foundations, results, and interpretation. Ph.D. dissertation, University of Chicago.

----- . 2006. Three Concepts of decidability for general subsets of uncountable spaces. Theoretical Computer Science 351: 2-13.

Poincaré, Jules-Henri. [1892-99] 1957. Les Mèthodes Nouvelles de la Méchanique Céleste. New York: Dover Publications.

Putnam, Hilary. 1971. Philosophy of Logic. New York: Harper Torch Books.

----- . 1973. Meaning and Reference. Journal of Philosophy 70: 699-711.

---- . 1975a. The meaning of 'meaning.' In Keith Gunderson, ed., Language, Mind, and Knowledge: Minnesota Studies in the Philosophy of Science 7. Minneapolis: University of Minnesota Press, 131-193.

---- . 1975b. What is mathematical truth? In Mathematics, Matter and Method: Philosophical Papers, vol. 1. Cambridge, Massachussetts: Cambridge University Press, 60-78.

Quine, W. V. [1948] 1953. On what there is. In From a Logical Point of View. Cambridge, Massachussetts: Harvard University Press, 1-19.

----- . 1951. Two Dogmas of Empiricism. The Philosophical Review 60: 20-43.

Rabinovitch, Nachum L. 1970. Rabbi Hasdai Crescas (1340-1410) on numerical infinities. Isis 61: 224-230.

Russell, Bertrand. [1903] 1992. The Principles of Mathematics. London: Routledge.

Sambursky, Samuel. 1959. Physics of the Stoics. London: Rooutledge.

Sider, Theodore. 2001. Criteria of Personal Identity and the Limits of Conceptual Analysis. Philosophical Perspectives 15: 189-209.

---- . Forthcoming. Ontological realism. In David Chalmers, David Manley, and Ryan Wasserman, eds., Metametaphysics. Oxford: Oxford University Press. Available at http://www.tedsider.org.

Sklar, Lawrence. 1993. Physics and Chance: Philosophical Issues in the Foundations of Statistical Mechanics. Cambridge: Cambridge University Press.

Steele, Donald A. 1950. Introduction to Paradoxes of the Infinite, by Bernard Bolzano, 1-53. London: Routledge. 
Tait, William W. 1996. Frege versus Cantor and Dedekind: On the concept of number. In Tait, ed., Early Analytic Philosophy: Frege, Russell, Wittgenstein (Essays in Honor of Leonard Linsky). Chicago: Open Court.

---- . 2000. Cantor's Grundlagen and the paradoxes of set theory. In Gila Sher and Richard Tieszen, eds., Between Logic and Intuition: Essays in Honor of Charles Parsons. Cambride: Cambridge University Press, 269-290.

Thomas, Ivo. 1958. A $12^{\text {th }}$ century paradox of the infinite. Journal of Symbolic Logic 23: 133-134.

Waismann, Friedrich. 1945. Verifiability. Proceedings of the Aristotelian Society, Supplementary Volume XIX: 119-150.

Wilder, Raymond L. Evolution of Mathematical Concepts: An Elementary Study. New York: John Wiley \& Sons, Inc.

Wittgenstein, Ludwig. 1953. Philosophical Investigations. Translated by G. E. M. Anscombe. New York: Macmillan Company. 